\title{
Independent Effects of Obesity and Insulin Resistance on Postprandial Thermogenesis in Men
}

Karen R. Segal," Jeanine Albu, Alexander Chun,* Albert Edano,* Brigido Legaspi, and F. Xavier Pi-Sunyer

*Division of Pediatric Cardiology, Department of Pediatrics, Mount Sinai School of Medicine, New York 10029

\section{Abstract}

The putative blunted thermogenesis in obesity may be related to insulin resistance, but insulin sensitivity and obesity are potentially confounding factors. To determine the independent effects of obesity and insulin resistance on the thermic effect of food, at rest and after exercise, lean and obese men were matched at two levels of insulin sensitivity determined by insulin-stimulated glucose disposal (milligrams per kilogram fatfree mass [FFM] per minute) during the euglycemic, hyperinsulinemic (40 $\mathrm{mU} / \mathrm{m}^{2} \cdot \mathrm{min}$ ) clamp: $5.4 \mathrm{mg} / \mathrm{kg}$ FFM for the lean and obese groups with low insulin sensitivity, and $8.1 \mathrm{mg} / \mathrm{kg}$ FFM for the groups with high insulin sensitivity. The two lean groups were matched for percent fat ( $\sim 15 \pm 1 \%$ fat $)$, as were the two obese groups ( $\sim 33 \pm 2 \%$ fat). Energy expenditure was measured for $3 \mathrm{~h}$ in the fasting state and for $3 \mathrm{~h}$ after a $720-\mathrm{kcal}$ mixed meal, each at rest and immediately after $1 \mathrm{~h}$ of cycling at $100 \mathrm{~W}$. The thermic effect of food (TEF) was calculated as the postprandial minus fasting energy expenditure (kcal/3 h) during rest and after exercise. During rest, TEF was blunted by both obesity $(24 \pm 5$ and $34 \pm 6 \mathrm{kcal} / 3 \mathrm{~h}$ for obese groups with low and high insulin sensitivity vs. $56 \pm 6$ and $74 \pm 6 \mathrm{kcal} / 3 \mathrm{~h}$ for the lean groups with low and high insulin sensitivity; $P<0.01$ lean vs. obese) and insulin resistance (insulin-resistant less than insulin-sensitive, at both levels of obesity; $P<0.01)$. After exercise, TEF was also impaired in the obese ( $47 \pm 6$ and $44 \pm 5$ $\mathrm{kcal} / 3 \mathrm{~h}$ for the insulin-resistant and -sensitive groups) and in the lean insulin-resistant $(55 \pm 5 \mathrm{kcal} / 3 \mathrm{~h})$, compared with the lean insulin-sensitive men $(71 \pm 3 \mathrm{kcal} / 3 \mathrm{~h}), P<0.01$. Compared with rest, TEF after exercise was improved, but not normalized, in both obese groups $(P<0.05)$, but unchanged in the lean groups. These results suggest that both insulin resistance and obesity are independently associated with impaired TEF at rest, but the responsiveness of thermogenesis to exercise before a meal is related to the obese state and not independently to insulin resistance per se. (J. Clin. Invest. 1992. 89:824-833.) Key words: energy expenditure • euglycemic hyperinsulinemic clamp • exercise $\bullet$ glucose metabolism • obesity • thermogenesis

Portions of this work were presented in abstract form to the American Federation for Clinical Research, Seattle, WA, 1991.

Drs. Albu, Legaspi, and Pi-Sunyer are affiliated with The Obesity Research Center, St. Luke's-Roosevelt Hospital Center, New York 10019.

Address reprint requests to Dr. Segal, Box 1201, Mount Sinai School of Medicine, 1 Gustave Levy Place, New York, NY 10029.

Received for publication 14 August 1991 and in revised form 7 November 1991.

J. Clin. Invest.

(c) The American Society for Clinical Investigation, Inc.

$0021-9738 / 92 / 03 / 0824 / 10 \$ 2.00$

Volume 89, March 1992, 824-833

\section{Introduction}

The existence and quantitative importance of an association between obesity and defective thermogenesis, which is a diminished rise in energy expenditure in response to infused or ingested nutrients, is controversial: roughly equal numbers of studies have confirmed and refuted a defect in thermogenesis in human obesity (1-10). These conflicting findings can be attributed in part to differences in experimental methodologies, and prior dietary and weight status, as well as heterogeneity among obese humans. The thermogenic response to nutrients consists of an obligatory component, which is the energy cost of digesting, absorbing, processing, and storing the nutrients, and a facultative component, which is the energy expended in excess of the obligatory, metabolic demands (11), and includes stimulation of the sympathetic nervous system, protein turnover, substrate cycling, and sodium pumping (11, 12). The thermic response to the protein content of a mixed meal is large, despite the fact that neither insulin nor sympathetic stimulation is involved. The putative blunted thermic responses to infused and oral glucose in obese and diabetic subjects are related to insulin resistance which leads to impaired insulin-mediated glucose disposal $(7,13)$. Blunted thermogenesis during the euglycemic hyperinsulinemic clamp in obese subjects is associated with a reduced rate of total glucose uptake and storage, which has a greater energy cost than glucose oxidation.

Since insulin sensitivity decreases with increasing obesity $(14,15)$, the two parameters are tightly intercorrelated and therefore, potentially confounding factors. On the one hand, Bogardus et al. (16) reported that, up to $\sim 28 \%$ body fat, insulin sensitivity (determined by the glucose clamp) was negatively related to percent body fat, but above $\sim 28 \%$ body fat there was no correlation between in vivo insulin action and degree of obesity. On the other hand, there is a strong negative correlation between percent body fat and the thermic effect of food throughout the entire range of obesity $(8,17)$. This suggests that there may be an independent component in the relationship between fatness and impaired thermogenesis that is unassociated with the insulin resistance in obesity. The intercorrelation between obesity and insulin resistance poses interpretive difficulty: to the extent that these two factors are predictably linearly or nonlinearly related, they are confounding factors. Statistical control can be applied by such techniques as partial correlation in order to distinguish between effects of obesity and of insulin resistance; however, in cases where variables are colinear, it is impossible to distinguish the isolated effects of each variable (18). Thus, the specific relationship of obesity to thermogenesis and glucose metabolism, independent from the relationship of obesity to alterations in insulin sensitivity and insulin-mediated glucose metabolism, is unclear. 
There is also considerable controversy regarding the impact of exercise on the thermic response to a meal. Some studies suggest that exercise enhances the thermic response to a meal in lean but not obese subjects, whereas others fail to confirm an effect of exercise on postprandial thermogenesis even in lean subjects $(1,19-22)$. These conflicting findings may be attributable in part to differences in meal size and composition, the timing of meal and exercise, intensity and duration of exercise, and confounding effects of imposing the thermic effects of food and exercise on diurnal changes in metabolic rate. Previous studies from our laboratory have shown that the thermic effect of food was greatest in obese subjects when the meal was taken after a 30-min exercise bout, compared with no exercise and the meal before exercise sequence, although it was still blunted compared to the lean subjects (23). The mechanism by which a bout of exercise may alter postprandial thermogenesis may involve exercise-induced changes in insulin sensitivity and glucose metabolism. Although there is evidence that exercise alters the thermic response to a subsequent meal, especially in the obese, the independent effects of obesity and insulin resistance on postexercise postprandial thermogenesis are unknown.

The objective of the present study was to determine the independent effects of obesity and insulin resistance on thermogenesis by use of a rigorously controlled experimental model in which the natural intercorrelation between obesity and insulin resistance is uncoupled. Obesity was crossed with insulin sensitivity in a $2 \times 2$ factorial design in which obesity (lean or obese) and insulin sensitivity (low or high) were completely independent factors and the thermic effect of a mixed meal at rest and after exercise, and the thermic effect of infused glucose and the pathways of insulin-stimulated glucose disposal were studied. This design enabled us to delineate the independent and interactive effects of obesity and insulin resistance by comparing thermogenesis in lean and obese men who were matched precisely with respect to level of insulin sensitivity.

\section{Methods}

Subjects. 16 lean and 16 obese men aged $25-40 \mathrm{yr}$ participated in this study. The lean men were $<18 \%$ body fat and had no personal or family history of obesity, and the obese men were $>28 \%$ body fat, determined by hydrostatic weighing. Four groups were recruited, two lean and two obese groups. At each level of obesity (lean or obese), a subset of men who had low insulin sensitivity and a subset of men who had high insulin sensitivity were selected. Insulin sensitivity was determined by glucose disposal (milligrams per kilogram fat-free mass $[\mathrm{FFM}]^{1}$ per minute) during the euglycemic hyperinsulinemic clamp. The results of the euglycemic hyperinsulinemic clamp were used as a criterion for inclusion in the study. Men with insulin-stimulated glucose disposal values of 4-6 mg/ $\mathrm{kg} \mathrm{FFM} \cdot \min (300-350 \mathrm{mg} / \mathrm{min})$ were considered to have low insulin sensitivity (insulin resistant); men with values of $8-9 \mathrm{mg} / \mathrm{kg} \mathrm{FFM} \cdot \min (500-600 \mathrm{mg} / \mathrm{min})$ were considered to have high insulin sensitivity (insulin sensitive). The two lean groups were matched on percent body fat (15\%) and body weight, as were the two obese groups (33\% fat), while the lean and obese groups were matched on insulin sensitivity at two levels $(\sim 5$ and $8 \mathrm{mg} / \mathrm{kg}$ FFM $\cdot \min$ ).

All four groups were matched with respect to age, FFM, and maximal aerobic capacity. Men who engaged in regular aerobic exercise were not accepted into the study in order to eliminate level of cardiorespiratory fitness as a possible intervening variable. All of the men were

1. Abbreviations used in this paper: FFM, fat-free mass; RMR, resting metabolic rate; $R Q$, respiratory quotient. weight stable with no more than a 2-kg weight change over the previous $6 \mathrm{mo}$. They were healthy, normotensive nonsmokers with normal glucose tolerance (24). The subjects consumed a weight-maintenance diet containing at least $300 \mathrm{~g}$ of carbohydrate per day before and throughout the duration of their participation in the study. The protocol was approved by the Institutional Review Board of the Mount Sinai School of Medicine and written informed consent of all subjects was obtained.

Densitometry. Body fat content and FFM were determined by hydrodensitometry. Body density was determined by hydrostatic weighing according to the method described by Akers and Buskirk (25). Residual lung volume was estimated by the closed-circuit oxygen dilution method (26). Percent body fat, fat weight, and fat-free weight were derived from body density by use of the Siri equation (27).

Aerobic fitness test. Maximal oxygen consumption $\left(\mathrm{VO}_{2} \max \right)$ and submaximal aerobic fitness were determined by a continuous multistage exercise test on an electromagnetically braked cycle ergometer (Robert Bosch GmbH, Berlin, FRG). The subjects began cycling at a rate of $60 \mathrm{rpm}$ with zero external resistance (unloaded cycling). The work rate was increased in $30-\mathrm{W}$ increments every 2 min until volitional exhaustion was reached. Ventilatory measurements were made continuously by open-circuit respirometry with use of a Horizon Metabolic Measurement Cart (Sensormedics Corp., Anaheim, CA). For each measurement, oxygen consumption $\left(\mathrm{VO}_{2}\right)$, carbon dioxide production $\left(\mathrm{VCO}_{2}\right)$, minute ventilation (VE), and the ventilatory equivalent for $\mathrm{O}_{2}\left(\mathrm{VE} / \mathrm{VO}_{2}\right)$ were obtained. Standard criteria for achieving a true $\mathrm{VO}_{2}$ max were applied. Submaximum aerobic fitness was determined by estimation of the ventilatory threshold from the test data. The ventilatory threshold, in healthy individuals, is the highest work rate or $\mathrm{VO}_{2}$ before $\mathrm{VE}$ increases out of proportion to $\mathrm{VO}_{2}$, owing to stimulation of ventilation by non-metabolically produced $\mathrm{CO}_{2}$ which may derive from the buffering of lactic acid (28).

Oral glucose tolerance test (OGTT). After a fasting blood sample was drawn, a 75-g glucose load was given and venous blood samples were drawn at 30 -min intervals for $2 \mathrm{~h}$. The plasma was analyzed for glucose and insulin and the integrated areas under the glucose and insulin curves were calculated.

Euglycemic hyperinsulinemic insulin clamp. The euglycemic hyperinsulinemic clamp procedure was used to assess in vivo insulin sensitivity (29), in order to recruit groups of lean and obese men at each of two levels of insulin sensitivity. The subjects were tested at 7:00 a.m. after an overnight $12-\mathrm{h}$ fast, having abstained from any exercise for 4-5 $\mathrm{d}$ before the test. When the euglycemic hyperinsulinemic clamp is combined with simultaneous indirect calorimetry, the thermic effect of infused glucose and insulin, which is the increase in energy expenditure during the clamp, can be determined and the total glucose uptake can be partitioned into glucose oxidation and nonoxidative glucose disposal (storage).

An intravenous catheter was inserted in retrograde fashion into a hand vein and the hand was placed in a heated box $\left(>70^{\circ} \mathrm{C}\right)$ to provide arterialized venous blood samples. Another catheter was placed in the antecubital vein of the other arm for infusion of glucose and insulin. A priming dose of $25 \mu \mathrm{Ci}$ of $\left[3-{ }^{3} \mathrm{H}\right]$ glucose (New England Nuclear, Boston, MA) was administered, followed by continuous infusion of 0.25 $\mu \mathrm{Ci} / \mathrm{min}$ of $\left[3{ }^{3} \mathrm{H}\right]$ glucose for $2 \mathrm{~h}$, to estimate hepatic glucose production in the basal state, and for the following $2 \mathrm{~h}$ to determine hepatic glucose production during the clamp. The $\left[3-{ }^{3} \mathrm{H}\right]$ glucose was purified by HPLC, and verified to be $99.0 \%$ pure. Arterialized blood samples were obtained at 15 -min intervals for the first $90 \mathrm{~min}$ and every $5 \mathrm{~min}$ during the last $30 \mathrm{~min}$ of this control period to measure the plateau steady-state plasma glucose specific activity. After the 2-h control period, a primed continuous $\left(40 \mathrm{mU} / \mathrm{m}^{2} \cdot \mathrm{min}\right)$ infusion of regular human insulin (Humulin R, Eli Lilly \& Co., Indianapolis, IN) was administered for $2 \mathrm{~h}$ to raise and maintain the insulin concentration at $\sim 100$ $\mu \mathrm{U} / \mathrm{ml}$. The plasma glucose level was maintained at $\sim 90 \mathrm{mg} / \mathrm{dl}$ by adjusting the rate of infusion of a $20 \%$ dextrose in water solution (29). Plasma $\left[3-{ }^{3} \mathrm{H}\right]$ glucose specific activity was measured at 15 -min intervals for the first $90 \mathrm{~min}$ of the insulin infusion and at 5 -min intervals during the last $30 \mathrm{~min}$ of the study. Indirect calorimetry was applied for 
the last $30 \mathrm{~min}$ of the baseline period and again during the last $30 \mathrm{~min}$ of the clamp in order to obtain measurements of energy expenditure, using the Horizon metabolic cart. The subjects voided before and after the test for measurement of urinary nitrogen.

Calculations. The rate of appearance $(\mathrm{Ra})$ and disappearance $(\mathrm{Rd})$ of glucose in the plasma was calculated from the $\left[3-{ }^{3} \mathrm{H}\right]$ glucose specific activity using the equations of Steele (30) in the steady-state form for the last $30 \mathrm{~min}$ of the basal period, and in the non-steady-state form, as validated by Radziuk et al. (31) during the last 30 min of the clamp. The last $30 \mathrm{~min}$ of the euglycemic clamp study was used to calculate the rate of glucose disposal (Rd), by the entire body. The glucose distribution volume of $40 \mathrm{ml} / \mathrm{kg}$ body weight was assumed. The rate of total glucose disposal during the clamp (Rd) was considered to represent the sum of the rates of glucose infusion, corrected for the glucose space, and the residual endogenous (hepatic) glucose production, if any.

The nonprotein respiratory quotient was calculated from the respiratory exchange data and urinary nitrogen production rates. The rates of carbohydrate and lipid oxidation were calculated according to the procedure of Lusk (32), which is based on a nonprotein respiratory quotient of 0.707 for $100 \%$ fat oxidation and 1.000 for $100 \%$ carbohydrate oxidation. The thermic effect of glucose was calculated as the difference between the energy expenditure during the last $30 \mathrm{~min}$ of the baseline period and the last $30 \mathrm{~min}$ of the insulin/glucose infusion. Nonoxidative glucose disposal, which includes storage as glycogen, conversion to three-carbon compounds, and conversion to lipid, was calculated as the difference between the rate of glucose oxidation and total uptake of glucose.

Thermogenesis tests. The thermic effect of food at rest and after $1 \mathrm{~h}$ of cycling exercise at $100 \mathrm{~W}$ was determined with a protocol that consisted of four tests on nonconsecutive days, the order of which was randomized. Baseline postabsorptive metabolic rate was measured on each test day, after a 30-min rest period.

(a) Postabsorptive resting metabolic rate (RMR) was measured for the last $6 \mathrm{~min}$ of every half-hour for $3 \mathrm{~h}$ while the subjects sat quietly.

(b) Postprandial RMR was measured for the last 6 min of every halfhour for $3 \mathrm{~h}$ after the subjects consumed a $720-\mathrm{kcal}$ liquid mixed meal (Sustacal, Mead Johnson, Evansville, IN) which was $24 \%$ protein, $21 \%$ fat, and $55 \%$ carbohydrate. The test meal was consumed within $5 \mathrm{~min}$.

(c) Postabsorptive exercise: metabolic rate measured during $1 \mathrm{~h}$ of cycling at $100 \mathrm{~W}$ and for $3 \mathrm{~h}$ after exercise, as above.

(d) Postprandial exercise: The test meal was given immediately after 1 $\mathrm{h}$ of exercise at $100 \mathrm{~W}$; postprandial metabolic rate measured for the last $6 \mathrm{~min}$ of every half-hour for $3 \mathrm{~h}$ after exercise.

Thus, for both the resting and postexercise conditions a fasting trial served as the control for the postprandial trial. For each measurement the respiratory exchange ratio $\left(\mathrm{VCO}_{2} / \mathrm{VO}_{2}\right)$ was calculated and results were converted to kilocalories by use of the Weir equation (33). The thermic effect of food was calculated as the postprandial minus fasting energy expenditure over $3 \mathrm{~h}$ for the resting and postexercise conditions. It has been previously shown that the thermic response to a liquid mixed meal is neither delayed nor more prolonged in obese insulin-resistant men compared with lean men and although the entire thermic effect is not measured over $3 \mathrm{~h}$, a study duration of $3 \mathrm{~h}$ provides an unbiased estimate of the magnitude of the difference between the thermic response to a meal in lean and obese subjects (34). Recently, the measurement of the thermic effect of food in our laboratory was determined to be highly reproducible from day to day (35).

Assay procedures. Plasma glucose levels were measured with use of a glucose analyzer (model II, Beckman Instruments, Inc., Fullerton, CA) $(36,37)$. Plasma insulin was measured by radioimmunoassay with charcoal absorption with use of a human insulin standard (37). Plasma [3- $\left.{ }^{3} \mathrm{H}\right]$ glucose specific activity was determined by the method of Katz and Dunn (38). Urinary nitrogen was determined by the Kjeldahl method (39).

Design and statistical analyses. Comparison of the thermic effect of food at rest and after exercise in the lean and obese men with low and high insulin sensitivity was made by application of a five-way analysis of variance in a $2 \times 2 \times 2 \times 2 \times 6$ factorial design with two betweensubject factors and three within-subject factors (40). The between-subject factors were obesity (lean or obese) and level of insulin sensitivity (low or high). The within-subject factors were exercise (rest or exercise), food (meal or no meal), and time (the six half-hourly measurements). The data were expressed both as $\mathrm{VO}_{2}$ and as caloric expenditure. Signifcant F-ratios from the analyses of variance were followed by post-hoc comparisons according to the Neuman-Keuls procedure, using the appropriate error terms from the analyses of variance (40).

Direct assessment of the impact of obesity and insulin resistance or sensitivity on the thermic effect of food at rest and after exercise was made by applying a three-way analysis of variance with repeated measures to the calculated thermic effect of food over $3 \mathrm{~h}$ using obesity, level of insulin sensitivity (resistant or sensitive), and exercise (rest or after exercise) as the factors. Significant F-ratios were followed by the appropriate comparisons among cell means.

Comparisons of aerobic fitness, body composition, resting metabolic rate, and data derived from the glucose clamp test, among the four groups were made by applying $2 \times 2$ two-way analyses of variance using obesity and insulin sensitivity as the factors. Significant interaction effects were followed by comparisons among the cell means, using the appropriate error terms. Associations among the thermic effect of infused glucose, glucose uptake and storage, and the thermogenesis data, were determined by regression procedures. Before pooling the data from the four groups, the correlations within each group were examined and data were only pooled if the direction and strength of the correlations were similar among all groups (40). The 0.05 level of significance was used.

\section{Results}

The subjects' characteristics are shown in Table I. There were no differences among the four groups with respect to age, height, FFM, or maximal or submaximal aerobic fitness. The two lean groups were closely matched for percent body fat and total body weight as were the two obese groups. As anticipated, resting metabolic rate (see Table I) was not different among any of the groups, since they were matched for FFM. The day-today coefficient of variation in the baseline resting metabolic rate was $<3 \%$.

There were no significant effects of either obesity or insulin sensitivity on basal hepatic glucose production $(173 \pm 9$ and $160 \pm 8 \mathrm{mg} / \mathrm{min}$ in the lean groups with low and high insulin sensitivity, respectively; and $182 \pm 6$ and $170 \pm 7 \mathrm{mg} / \mathrm{min}$ in the obese groups with low and high insulin sensitivity) although there was a trend for slightly higher levels in the insulin-resistant compared with the insulin-sensitive men $(P=0.11$, NS). Steady-state plasma glucose levels during the euglycemic hyperinsulinemic clamp were $90 \pm 2$ and $88 \pm 1 \mathrm{mg} / \mathrm{dl}$ for the lean men with low and high insulin sensitivity, and $88 \pm 1$ and $89 \pm 2$ $\mathrm{mg} / \mathrm{dl}$ in the obese groups with low and high insulin sensitivity, respectively. Steady-state plasma insulin levels were not significantly different among the groups $(116 \pm 8$ and $115 \pm 9 \mu \mathrm{U} / \mathrm{ml}$ for the lean groups with low and high insulin sensitivity, respectively, and $131 \pm 12$ and $109 \pm 7 \mu \mathrm{U} / \mathrm{ml}$ for the obese groups with low and high insulin sensitivity). Total glucose disposal during the euglycemic hyperinsulinemic clamp, shown in Fig. 1, was similar for the lean and the obese men at each of the two levels of insulin sensitivity. This, of course, was the experimental design of the study. Similar patterns of results were obtained when the glucose disposal data were expressed relative to FFM or in absolute form as milligrams per minute. Although the lean and obese groups were matched for total glucose disposal, 


\begin{tabular}{|c|c|c|c|c|}
\hline & \multicolumn{2}{|c|}{ Lean } & \multicolumn{2}{|c|}{ Obese } \\
\hline & Resistant & Sensitive & Resistant & Sensitive \\
\hline Age & $31 \pm 2$ & $30 \pm 3$ & $28 \pm 1$ & $31 \pm 2$ \\
\hline Height $(\mathrm{cm})$ & $178 \pm 3$ & $177 \pm 2$ & $176 \pm 3$ & $173 \pm 2$ \\
\hline Weight $(k g)^{*}$ & $78.7 \pm 3.5$ & $77.1 \pm 2.3$ & $100.2 \pm 4.5$ & $94.2 \pm 4.4$ \\
\hline Percent body fat* & $15.8 \pm 1.0$ & $15.4 \pm 0.9$ & $34.0 \pm 1.4$ & $32.5 \pm 1.5$ \\
\hline FFM $(k g)$ & $66.1 \pm 2.7$ & $65.1 \pm 1.7$ & $65.8 \pm 2.3$ & $64.2 \pm 2.5$ \\
\hline \multicolumn{5}{|l|}{ Aerobic fitness } \\
\hline \multicolumn{5}{|l|}{ Maximal aerobic power } \\
\hline Workload $(W)$ & $247 \pm 9$ & $274 \pm 16$ & $258 \pm 13$ & $241 \pm 6$ \\
\hline $\operatorname{Max} \mathrm{VO}_{2}(\mathrm{ml} / \mathrm{min})$ & $2,926 \pm 160$ & $3,075 \pm 122$ & $3,221 \pm 126$ & $2,950 \pm 110$ \\
\hline$(\mathrm{ml} / \mathrm{kg} / \mathrm{FFM} / \mathrm{min})$ & $44.7 \pm 1.9$ & $47.3 \pm 1.8$ & $49.2 \pm 2.2$ & $46.4 \pm 2.4$ \\
\hline \multicolumn{5}{|l|}{ Ventilatory threshold } \\
\hline Power output $(W)$ & $113 \pm 7$ & $127 \pm 10$ & $130 \pm 9$ & $106 \pm 9$ \\
\hline $\mathrm{VO}_{2}(\mathrm{ml} / \mathrm{min})$ & $1,497 \pm 64$ & $1,554 \pm 126$ & $1,701 \pm 113$ & $1,481 \pm 81$ \\
\hline $\operatorname{RMR}(k c a l / m i n)$ & $1.35 \pm 0.04$ & $1.33 \pm 0.03$ & $1.39 \pm 0.11$ & $1.32 \pm 0.05$ \\
\hline
\end{tabular}

Means \pm SEM. ${ }^{*} P<0.01$ lean vs. obese.

there were significant main effects of both obesity and insulin resistance on endogenous (hepatic) glucose production (see Fig. 1). There was less suppression in both groups with low insulin sensitivity compared with the groups with high insulin sensitivity, and at each of the two fixed levels of insulin-stimulated glucose disposal, there was less suppression of hepatic glucose production by insulin in the obese compared with the lean men.

When the total glucose disposal was partitioned into oxidation and storage (see Fig. 2), glucose oxidation was not signifcantly different among the four groups, but glucose storage was significantly lower in the insulin-resistant compared with the insulin-sensitive groups. The rate of total body glucose disposal was significantly correlated with the rate of glucose storage $(r$ $=0.72, P<0.01)$, but not with the rate of glucose oxidation $(r$ $=0.29, \mathrm{NS}$ ).

The thermic effect of infused glucose was greater for both of the insulin-sensitive compared with the insulin-resistant groups (Fig. 3). At each level of insulin sensitivity there was a trend for a lower thermic effect of glucose in the obese than lean men, but this fell short of statistical significance $(P=0.12)$. The thermic effect of glucose correlated with total glucose disposal $(r=0.52)$; however, this correlation was due to a relationship between the thermic effect of glucose and the rate of glucose storage $(r=0.50 ; P<0.01)$, but not between the thermic effect of glucose and the rate of glucose oxidation $(r$ $=0.02 ; \mathrm{NS}$ ).

The oral glucose tolerance test results are shown in Table II. There was a significant effect of obesity on fasting plasma glucose and the glucose response area. Thus, at each level of insulin sensitivity, obesity was independently associated with higher fasting glucose and higher glucose response areas. Fasting plasma insulin levels and the insulin areas were independently increased by both obesity and insulin resistance: for the same level of obesity, insulin levels were higher in the insulinresistant than the insulin-sensitive men, and at each level of insulin sensitivity, insulin was higher in the obese than the lean men.

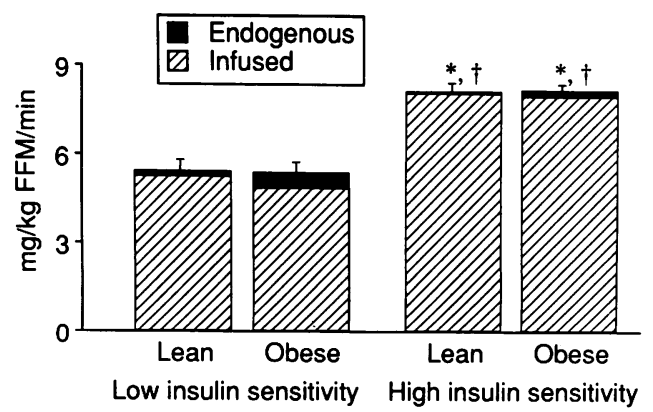

Figure 1. Total body glucose disposal during euglycemic hyperinsulinemic clamp. Total glucose disposal is partitioned into the rate of infused glucose and the rate of endogenous (hepatic) glucose production. ${ }^{*} P<0.01$ Low insulin sensitivity vs. High insulin sensitivity for total body glucose disposal, infused glucose, and endogenous glucose production. ${ }^{\dagger} P<0.05$ Obese vs. Lean for endogenous glucose production. Values are means \pm SEM.

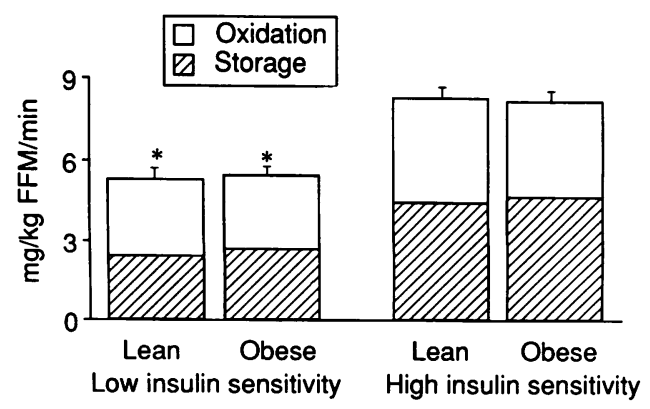

Figure 2. Total glucose disposal during euglycemic hyperinsulinemic clamp, partitioned into glucose oxidation (determined by indirect calorimetry) and nonoxidative glucose disposal (storage). ${ }^{*} P<0.01$ Low insulin sensitivity vs. High insulin sensitivity for glucose storage, and total glucose disposal. Values are means \pm SEM. 


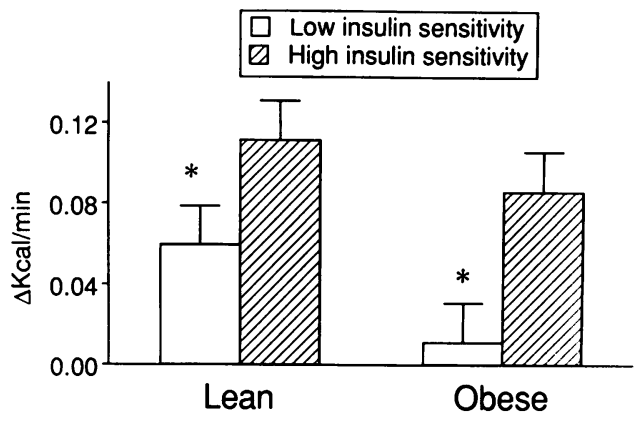

Figure 3. The thermic effect of infused glucose, expressed as the change in energy expenditure between the basal period and the last 30-min of the euglycemic hyperinsulinemic clamp. ${ }^{*} P<0.05$ Low insulin sensitivity vs. High insulin sensitivity. A trend for a lower thermic effect of glucose in the obese compared with the lean groups, at each level of insulin sensitivity, did not achieve statistical significance $(P=0.12)$. Values are means \pm SEM.

$\mathrm{VO}_{2}$ during exercise was $\sim 2.0$ liter in all groups. Since all groups were matched for aerobic fitness, the exercise used in the thermogenesis trials represented the same absolute and a similar relative intensity for all groups, i.e., roughly $67 \pm 1 \%$ of maximum aerobic capacity $\left(\mathrm{VO}_{2} \mathrm{max}\right)$.

Similar patterns of results were obtained when analyses of variance were applied to the $\mathrm{VO}_{2}$ or caloric expenditure data during the thermogenesis trials. The postabsorptive and postprandial $\mathrm{VO}_{2}$ data are shown in Figs. 4 (at rest) and 5 (postexercise). The factorial analysis of variance using obesity, insulin sensitivity, exercise, food, and time as the factors yielded significant effects for time, the food/time interaction, and the exercise/food by time interaction. These effects reflect a different time course in the thermic effect of food at rest and after exercise: there is a rise and subsequent fall in metabolic rate over the course of the 3-h postprandial period during the resting condition, whereas after exercise the thermic effect of food manifests as a reduction in the rate of decline in postexercise metabolic rate. None of the interactions between time and either obesity or insulin sensitivity were significant, indicating that the time course of the thermic effect of food did not vary significantly among any of the groups. Although the entire thermic response was not measured within the 3-h period, as shown in Figs. 4 and 5, the thermic response to the meal was neither delayed nor more prolonged in the groups with low

Table II. Oral Glucose Tolerance

\begin{tabular}{lccccc}
\hline & \multicolumn{2}{c}{ Lean } & & \multicolumn{2}{c}{ Obese } \\
\cline { 2 - 3 } \cline { 5 - 6 } \cline { 5 - 6 } & Resistant & Sensitive & & Resistant & Sensitive \\
\hline Fasting glucose $(m g / d l)^{*}$ & $91 \pm 2$ & $87 \pm 2$ & & $96 \pm 2$ & $96 \pm 3$ \\
Fasting insulin $(\mu U / m l)^{* \pm}$ & $21 \pm 4$ & $11 \pm 2$ & & $38 \pm 4$ & $21 \pm 4$ \\
Glucose area $(m g / d l)^{*}$ & $517 \pm 17$ & $457 \pm 22$ & & $564 \pm 30$ & $547 \pm 26$ \\
Insulin area $(\mu U / m l)^{* \neq}$ & $347 \pm 37$ & $196 \pm 16$ & & $699 \pm 51$ & $358 \pm 52$
\end{tabular}

Means \pm SEM. To convert glucose to millimolar, multiply by 0.056 ; to convert insulin to picomolar, multiply by 7.715 .

${ }^{*} P<0.01$ for effect of obesity, from two-way ANOVA: obese greater than lean.

${ }^{\ddagger} P<0.01$ for effect of insulin resistance, from two-way ANOVA: insulin-resistant greater than insulin-sensitive. compared with high insulin sensitivity, nor in the obese compared with lean men. Therefore, the calculated thermic effect of food, which is the difference between the postabsorptive and postprandial energy expenditure over $3 \mathrm{~h}$, under the resting and postexercise conditions, was used for further statistical analyses.

During rest, there were significant main effects for both obesity and insulin resistance, but no interaction. Thus, the thermic effect of food was reduced by both obesity and insulin resistance, independently. The thermic effect of food was lower in the lean men with low sensitivity compared with the lean men with high insulin sensitivity, lower in the obese men with low compared with high insulin sensitivity, and lower in both obese compared with both lean groups.

During the acute postexercise condition, there was a significant effect of obesity and an obesity by insulin resistance interaction, such that the thermic effect of food was lower in both obese compared with the lean groups, but whereas the thermic effect of food was greater for the lean insulin-sensitive compared with the lean insulin-resistant men, there were no differences between the two obese groups. Of more interest, though, is the comparison of the thermic effect of food at rest and after exercise (Fig. 6). There was a significant three-way interaction between obesity, insulin resistance, and exercise, such that there was no significant effect of exercise on the thermic effect of food in either of the lean groups, while for the obese groups, the thermic effect of food was significantly greater after exercise than at rest, and the most marked improvement was seen in the obese insulin-resistant group. Prior exercise significantly improved (but did not normalize) the thermic effect of food in both obese groups, but not in the lean insulin resistant group.

The respiratory quotient data, which are roughly indicative of the proportional rates of fat and carbohydrate oxidation, are shown in Table III. The respiratory quotients (RQs) were consistently significantly greater in the postprandial state than the postabsorptive state, and overall, were lower in the postexercise compared with the resting state. There was a significant obesity/insulin sensitivity/exercise interaction, such that the reduction in the postprandial RQ during the postexercise period compared with the resting condition was greater for obese, insulin-sensitive group than other groups. These results suggest that the magnitude of the postprandial increase in the relative rate of carbohydrate oxidation (and hence, the relative reduction in the proportional rate of fat oxidation) was lower after exercise than at rest in the obese, insulin-sensitive men than the other groups. For both obese groups, the lower postprandial $\mathrm{RQ}$ during the postexercise period compared with rest was associated with the enhanced thermic response.

The thermic effect of glucose was correlated with the thermic effect of food, both during resting $(r=0.40)$ and postexercise $(r=0.45)$ conditions. The thermic effect of infused glucose, insulin sensitivity, and the thermic effect of glucose were uncorrelated with level of aerobic fitness. However, it is important to point out that fitness was controlled experimentally by matching all of the groups closely with respect to their level of aerobic fitness.

\section{Discussion}

The present study made use of an experimental model in which the usual intercorrelation between obesity and insulin resistance was uncoupled in order to examine the independent and 
A. Lean, Low Insulin Sensitivity

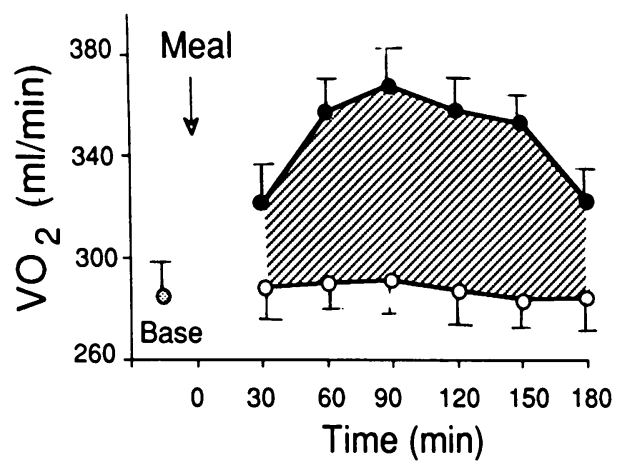

C. Obese, Low Insulin Sensitivity

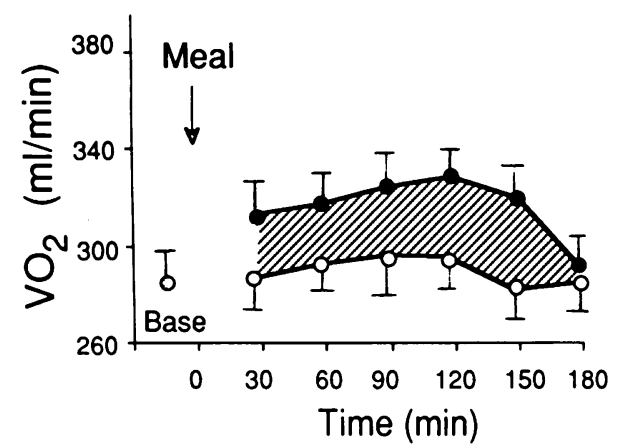

A. Lean, Low Insulin Sensitivity

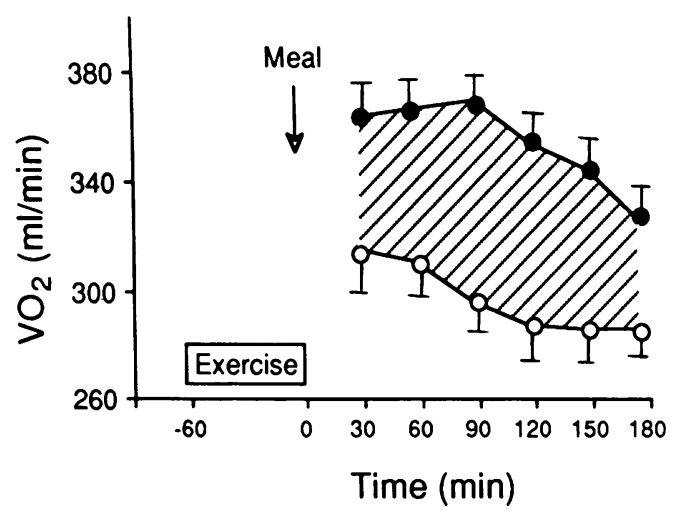

C. Obese, Low Insulin Sensitivity

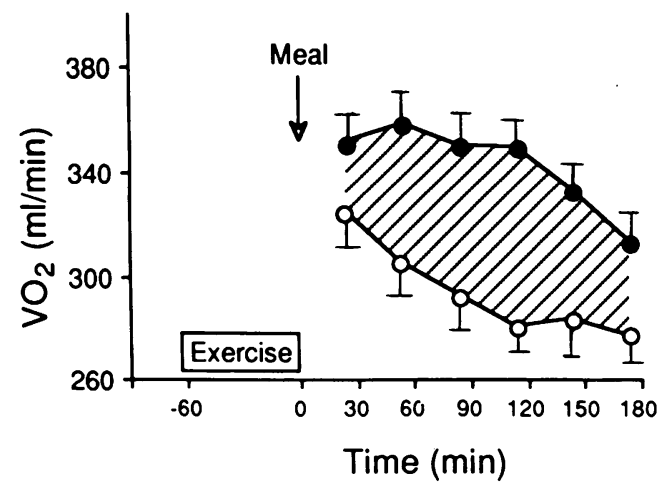

B. Lean, High Insulin Sensitivity

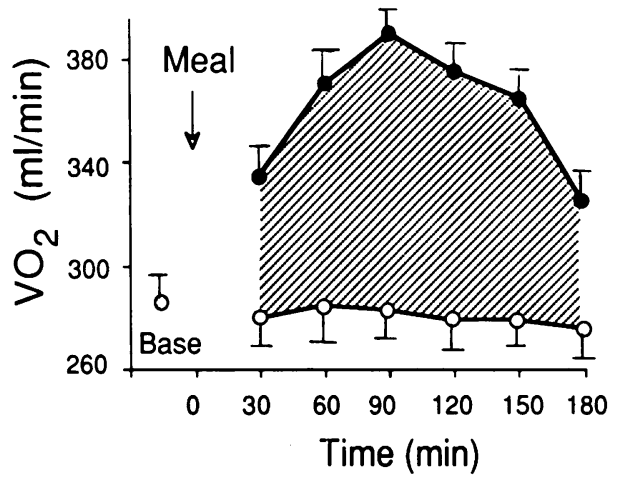

D. Obese, High Insulin Sensitivity

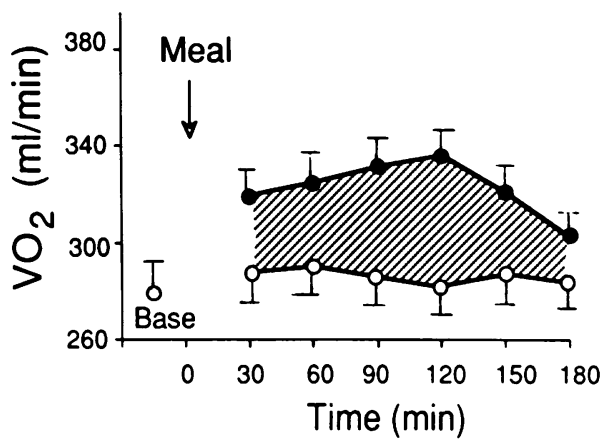

Figure 4. Oxygen consumption $\left(\mathrm{VO}_{2}\right)$ over $3 \mathrm{~h}$ in the postabsorptive state (o) and after a $720-\mathrm{kcal}$ meal (•) during the two resting thermogenesis trials. The shaded areas represent the thermic effect of the meal. The analysis of variance yielded significant main effects for obesity and insulin sensitivity $(P<0.05)$, reflecting the smaller thermic response to food in the obese compared with the lean men, and the groups with low compared with high insulin sensitivity. Values are means \pm SEM.

\section{B. Lean, High Insulin Sensitivity}

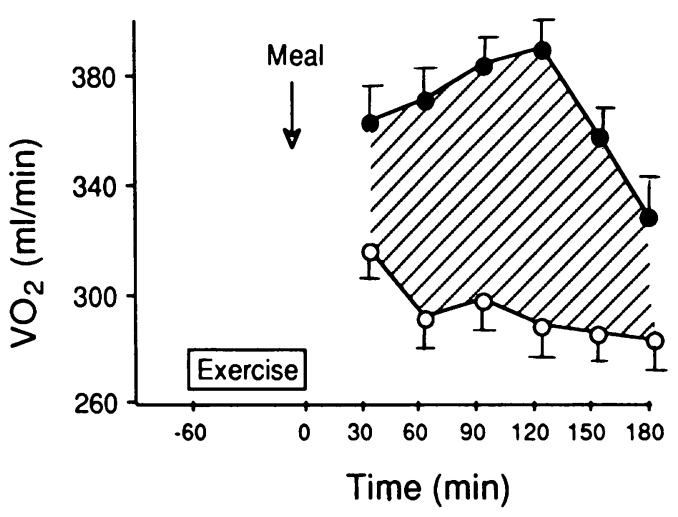

D. Obese, High Insulin Sensitivity

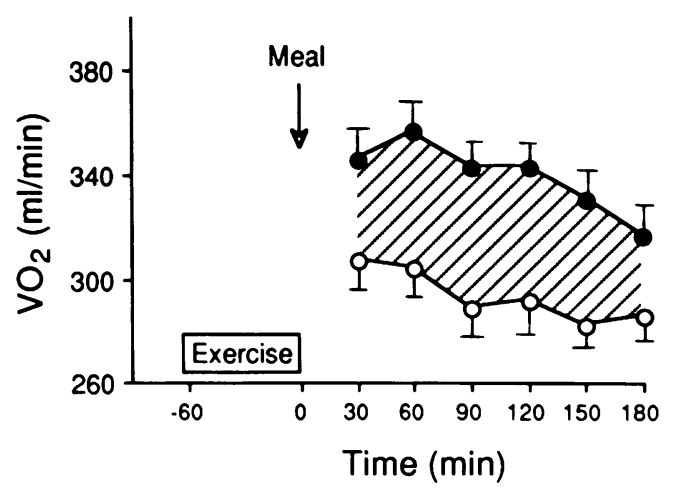

Figure 5. Oxygen consumption $\left(\mathrm{VO}_{2}\right)$ over $3 \mathrm{~h}$ in the postabsorptive state (0) and after a $720 \mathrm{kcal} \mathrm{meal} \mathrm{( \bullet )} \mathrm{dur-}$ ing the two postexercise thermogenesis trials. The shaded areas represent the thermic effect of the meal. The analysis of variance yielded a significant effects for obesity and the obesity/insulin sensitivity interaction $(P<0.05)$, such that the thermic effect of food was lower in the obese than the lean groups, and lower in the lean group with low compared with high insulin sensitivity, but not different between the two obese groups. Values are means \pm SEM. 


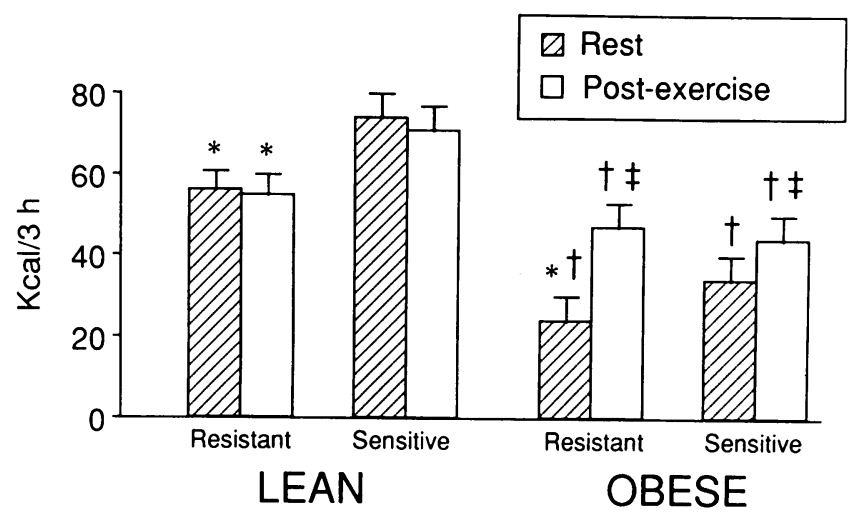

Figure 6. Thermic effect of food at rest and after exercise. ${ }^{*} P<0.05$ Insulin-resistant (low insulin sensitivity) vs. insulin-sensitive (high insulin sensitivity). 'Lean vs. obese ${ }^{\ddagger} P<0.05$ Rest vs. Post-exercise. Values are means \pm SEM.

interactive effects of these two factors on thermogenesis and glucose metabolism. Thus, in vivo insulin action and obesity were completely independent factors. The results of this study delineate for the first time the independent and interactive effects of obesity and insulin resistance on energy metabolism in weight stable lean and obese men. By design, all of the groups were matched for FFM, and therefore, neither obesity nor level of insulin sensitivity had any independent impact on the resting metabolic rate. Matching the groups on FFM ensured that unadjusted resting metabolic rates were comparable among groups before introducing the thermogenic stimulus of the meal. Since there is considerable evidence that skeletal muscle is a significant site for both thermogenesis and insulin resistance (41), observed differences among groups were not confounded by differences in the absolute mass of lean tissue.

Fasting plasma insulin levels and the insulin response to oral glucose were greater in the obese compared with the lean men at each level of insulin sensitivity. This finding supports the previous suggestion of Reaven et al. (42) that the direct relationship between plasma insulin levels and degree of obesity might be independent of insulin action. This implies that

Table III. Respiratory Quotient $\left(\mathrm{RQ}=\mathrm{VCO}_{2} / \mathrm{VO}_{2}\right)$ over $3 \mathrm{~h}$ during Thermogenesis Tests

\begin{tabular}{lcclll}
\hline & \multicolumn{2}{c}{ Lean } & & \multicolumn{2}{c}{ Obese } \\
\cline { 2 - 3 } \cline { 5 - 6 } & Resistant & Sensitive & & Resistant & Sensitive \\
\hline Rest & & & & & \\
$\quad$ Postabsorptive & $0.79 \pm 0.01$ & $0.80 \pm 0.02$ & & $0.80 \pm 0.01$ & $0.81 \pm 0.02$ \\
$\begin{array}{c}\text { Postprandial* } \\
\text { Postexercise }\end{array}$ & $0.85 \pm 0.01$ & $0.87 \pm 0.02$ & & $0.84 \pm 0.01$ & $0.85 \pm 0.02$ \\
Postabsorptive & $0.78 \pm 0.02$ & $0.81 \pm 0.02$ & & $0.78 \pm 0.02$ & $0.78 \pm 0.02$ \\
Postprandial*t & $0.84 \pm 0.02$ & $0.87 \pm 0.04$ & & $0.82 \pm 0.01$ & $0.81 \pm 0.01$
\end{tabular}

Means \pm SEM.

${ }^{*} P<0.01$ for effect of food (from ANOVA); postprandial greater than postabsorptive.

${ }^{\ddagger} P<0.05$ for obesity/insulin sensitivity/exercise interaction (from ANOVA): Reduction in postprandial RQ during postexercise period compared with resting condition was greater for obese, insulin-sensitive group than other groups. the progressive hyperinsulinemia with increasing obesity may not be determined only by insulin resistance. As expected, hepatic glucose production was less suppressed by insulin infusion in the insulin-resistant compared with the insulin-sensitive group. However, we also found that at each of the two levels of insulin-stimulated glucose disposal, there was less suppression of hepatic glucose production by insulin in the obese compared with the lean men. Although previous studies have reported reduced suppression of hepatic glucose production in obese compared with lean individuals, the impact of obesity per se, independent of insulin resistance, on the effect of insulin on hepatic glucose production has never been studied. Our finding that obesity is independently associated with a reduced ability of insulin to suppress hepatic glucose production indicates a divergence between peripheral and hepatic insulin sensitivity under the influence of obesity. Rizza et al. (43) have suggested that chronic hyperinsulinemia itself may produce hepatic resistance to insulin. Thus, a common pathway may explain our findings of increased insulin levels in obesity for each level of insulin sensitivity and the reduced insulin-induced suppression of hepatic glucose production in the obese compared with the lean groups at each of the two levels of total body glucose disposal.

The results of this study demonstrate that the thermic effect of infused glucose during the glucose clamp is blunted in men with low compared with high insulin sensitivity, independent of obesity. The rate of glucose oxidation during the euglycemic hyperinsulinemic clamp was not significantly altered by either obesity or insulin sensitivity, but glucose storage was significantly reduced in both the lean and obese insulin-resistant groups compared with the insulin-sensitive groups. This supports previous findings that the blunted thermic response to glucose observed in obese or diabetic subjects is due largely to a reduced rate of nonoxidative glucose disposal secondary to insulin resistance (7). This reduced rate of glucose storage has been shown to be associated with alterations in muscle glycogen synthase activity, muscle capillary density, and muscle fiber type (15). The strong correlation of the thermic effect of infused glucose with the rate of nonoxidative glucose disposal but not with the rate of glucose oxidation is consistent with the greater energy cost of glucose storage than oxidation (44).

On the other hand, obesity and insulin resistance are both independently associated with an impaired thermogenic response to an ingested mixed meal at rest: the thermic effect of food was significantly lower in the groups with low compared with high insulin sensitivity, across both levels of obesity, and lower in the obese compared with the lean men, at both levels of insulin sensitivity. Thus, whereas the blunted thermic response to infused glucose seems to be predominantly determined by insulin resistance, and more specifically, related to a reduced rate of glucose storage, the thermic response to a mixed meal is influenced by both insulin resistance and obesity, individually. These divergent results, as well as the modest correlation between the thermic responses to infused glucose and to a meal $(r=0.40)$ suggest that there may be physiological differences in metabolic and thermogenic pathways between the glucose clamp and orally administered meals. For example, during the glucose clamp most of the glucose uptake occurs in skeletal muscle where it is converted to glycogen (45). In contrast, recent studies have shown that a large part of liver glycogen formation after a meal occurs by the indirect gluconeogenic pathway wherein ingested glucose is converted to lactate 
in muscle and thereafter released and taken up by liver and converted to glycogen (46). The cycling of glucose to three-carbon compounds has a greater energy cost than storage by the direct pathway or oxidation (47). Studies of the relationship between thermogenesis and insulin resistance have specifically focused on the thermic response to infused glucose. Although previous investigations have speculated that the blunted thermic response to meals in obese individuals may be a function of their insulin resistance, we observed different effects of insulin resistance and obesity on the thermic effect of infused glucose (no effect of obesity but a significant effect of insulin sensitivity) and the thermic response to an orally ingested mixed meal (significant effects of both obesity and insulin sensitivity).

Although the relationship between defective thermogenesis in obese and diabetic humans and is fairly well understood (4, 7), the mechanism by which obesity itself is independently linked to blunted thermogenesis in the present study is unclear. Other mechanisms for the thermic response to a meal include sympathetic stimulation, futile substrate cycling, and protein synthesis (12). While the importance of sympathetic activity in the differential thermic responses of lean and obese individuals remains controversial, there is evidence both that norepinephrine levels may be lower in obese than lean individuals and that obese subjects may be resistant to the thermogenic effect of norepinephrine $(5,48)$. Although insulin/glucose infusion is linked to activation of the sympathetic nervous system (49), Bazelmans et al. (50) demonstrated that in obesity insulin sensitivity is uncorrelated with parameters of norepinephrine metabolism. This supports the possibility that sympathetic nervous system activity may be the mechanism by which obesity, independent of insulin resistance, is associated with impaired thermogenesis.

The impact of acute exercise on the thermic effect of food was dependent on an obesity by insulin resistance interaction: thermogenesis after exercise was improved in the obese but not in the lean groups, with the most marked improvement in obese, insulin-resistant men. We anticipated that the thermic effect of food would be greater after exercise than at rest for the obese and the lean groups with low insulin sensitivity than in the groups with high insulin sensitivity, owing to improved insulin sensitivity induced by acute exercise in these insulin-resistant subjects. The exercise-induced improvement in postprandial thermogenesis could theoretically be related to an improvement in insulin sensitivity after exercise and an associated shift in the pathways of glucose disposal. Glycogen synthase, the regulatory enzyme involved in glycogen synthesis, is activated in proportion to the rate glucose uptake, both at rest and after glycogen-depleting exercise and muscle glycogen resynthesis is the principal pathway of oral glucose disposal after exercise. Since skeletal muscle is the principal tissue involved in obesity-related insulin resistance and a likely site for thermogenesis $(41,45)$, muscle may therefore also by a likely site for the metabolic factors underlying the exercise-induced changes in thermogenesis in the obese men. The increased thermic effect of food for the obese subjects after exercise might be explained by increased glucose uptake and glycogen synthesis in muscle, secondary to increased sensitivity to insulin induced by exercise. The improved postexercise thermic effect of food in the obese groups was associated with lower postprandial $R Q$ values compared with the resting, postprandial values. This suggests that the enhancement of the thermic effect of food by exercise is associated with a lower rate of postprandial carbohydrate oxidation in the postexercise state compared with rest. A relative reduction in the rate of carbohydrate oxidation and increase in fat oxidation, reflected in a lower postexercise postprandial RQ, could direct the ingested carbohydrate preferentially toward storage.

A bout of prior exercise did not enhance postexercise postprandial thermogenesis in the lean subjects, perhaps because they may already have been close to their peak capacity for thermogenesis at rest. This is consistent with previous reports that prior-exercise did not enhance insulin-mediated glucose disposal in lean subjects because they may already have been close to their peak capacity for glucose transport at rest $(51,52)$. Yet it is puzzling that the lean insulin-resistant subjects were unresponsive to the effect of prior exercise on the thermic effect of food. These results suggest that while insulin resistance has an important role in thermogenesis, particularly in the obese, factors other than exercise-induced improvement in insulin action may account for the responsiveness of thermogenesis to exercise in the obese. Amino acid release and protein synthesis, as well as substrate cycling involving glucose (formation of glycogen by recycling of glucose via lactate and other three-carbon compounds), may be accelerated after exercise and these futile cycles might play a role in the exercise-induced improvement in the thermic effect of food in the obese groups. The process of recycling, which consumes more energy than direct glucose to glycogen conversion, is probably accelerated after exercise, owing to increased utilization of gluconeogenic substrates (53). Residual sympathetic stimulation from exercise, or enhanced responsiveness to the effect of norepinephrine after exercise may also play a role in the improved thermic response to a meal after exercise (12).

It still remains unclear whether the blunted thermogenesis we observed is a consequence or a cause of both the obesity and insulin resistance. It would be of interest to follow the lean, insulin-resistant men longitudinally to determine whether the blunted thermogenesis predisposes them to the development of obesity. The magnitude of the thermogenic response to food in the lean insulin-resistant men was midway between the lean insulin sensitive men and the two obese groups. Thus, the thermic effect of food (at rest) was still greater in the lean insulin-resistant men than both obese groups. In this respect, it is possible that blunted thermogenesis plays less of a role in the propensity for weight gain in the lean insulin-resistant group.

Based on longitudinal observations of the relationship between insulin resistance and weight gain, Swinburn et al. (54) have proposed that insulin resistance may limit further weight gain, whereas individuals with greater insulin sensitivity are at greater risk to gain more weight. These findings might be explained by a negative feedback mechanism wherein body weight gain leads to increased insulin resistance which in turn protects against further weight gain. According to these observations, the insulin resistance in the lean men in our study may lower their risk of becoming obese, although the mechanism for such an effect is unclear (54). Despite the reduced thermogenesis in this group, the same mechanisms which underlie the finding that insulin-resistant Pima Indians gain less weight than obese insulin-sensitive ones may operate in such a fashion as to maintain the leanness in our insulin-resistant lean group. On the other hand, according to the hypothesis put forth by Arner (55), insulin resistance and the relative hyperinsulinemia in the lean insulin resistant men could lead to obesity by inhibition of insulin-sensitive lipolysis. 
The importance of blunted thermogenesis in obesity is still questionable because despite smaller increases in metabolic rate in response to thermic stimuli, total, absolute energy expenditure is generally greater in obese than lean people, owing to the fact that FFM, as well as fat mass is generally increased in obesity. The specific, quantitative role of blunted thermogenesis in the etiology and/or maintenance of obesity is unknown. Thorne et al. reported that the blunted thermic effect of food was increased and nearly normalized after weight loss, which suggested that the thermogenic defect is secondary rather than a primary pathogenic factor in human obesity (10). On the other hand, other studies have demonstrated that the defect in thermogenesis persists after weight loss (56). The magnitude of the difference of the thermic effect of a single meal is small, and thus, it is unlikely that a defective thermic response plays a role in short term energy balance. However, over long periods of time a subtle metabolic efficiency may favor the storage rather than the dissipation of energy. Thermogenesis is enhanced roughly $40-50 \%$ by acute exercise in the obese groups, but the absolute increment in total caloric expenditure is quite small (roughly 13-23 kcal/3 h); thus, the long-term significance of exercise-induced changes in thermogenesis is also uncertain. The mechanisms underlying the blunted thermogenesis in the obese as well as the relationships among defective thermogenesis, insulin resistance, and obesity are unresolved: it is not known whether both insulin resistance and defective thermogenesis are consequences of obesity that in a subtle way perpetuate the obesity or if insulin resistance leads to a defect in postprandial energy expenditure which predisposes an individual to obesity by means of increased metabolic efficiency. Insulin resistance itself could predispose to obesity by way of inhibition of fat oxidation or diminished thermogenesis, owing to a reduction in nonoxidative glucose disposal and the associated lower energy cost of oxidative glucose metabolism. It is also possible that over long periods of time the blunted thermogenesis could contribute to the onset, persistance or worsening of the obese state by a subtle energy conserving defect.

In summary, the results of the present study indicate that although resting metabolic rate was not affected by either obesity or insulin resistance, the thermic effect of infused glucose is blunted by insulin resistance and not related to obesity per se, whereas the thermic response to ingested nutrients was significantly reduced by both obesity and insulin resistance, independently. Longitudinal investigations are needed to resolve the nature of the interrelationships among obesity, insulin resistance, and thermogenesis. For example, it would be important to document whether the insulin-resistant lean subjects are metabolically predisposed to become obese and whether the obese, insulin-resistant men are more or less likely to become even fatter than the obese, insulin-sensitive men. Long-term followup of these subjects may therefore provide further insights regarding the impact of impaired thermogenesis and insulin resistance on body weight regulation as well as further information regarding the underlying relationships among insulin resistance, obesity, and energy metabolism.

\section{Acknowledgments}

The authors thank Mrs. Yim Dam and Mrs. Yang Hee for their valuable technical assistance.

This study was supported by the National Institutes of Health (grant DK-37948). All biochemical assays were performed at The Obe- sity Research Center, St. Luke's-Roosevelt Hospital Center (National Institutes of Health grant DK-26687).

\section{References}

1. Blaza, S., and J. S. Garrow. 1983. Thermogenic response to temperature, exercise and food stimuli in lean and obese women, studied by 24-hour direct calorimetry. Br. J. Nutr. 49:171-180.

2. D'Alessio, E. C., M. A. Kayle, K. J. Smalley, M. Polansky, Z. V. Kendrick, L. R. Owen, M. C. Bushman, G. Boden, and O. E. Owen. 1988. Thermic effect of food in lean and obese men. J. Clin. Invest. 81:1781-1789.

3. Felig, P., J. J. Cunningham, M. Levitt, R. Hendler, and E. Nadel. 1983. Energy expenditure in obesity in fasting and postprandial state. Am. J. Physiol. 244:E45-E51.

4. Golay, A., Y. Schutz, J. P. Felber, R. A. DeFronzo, and E. Jequier. 1986. Lack of thermogenic response to glucose/insulin infusion in diabetic obese subjects. Int. J. Obesity. 10:107-116.

5. Jung, R. T., P. S. Shetty, and W. P. T. James. 1979. Reduced thermogenesis in obesity. Nature (Lond.). 279:322-323.

6. Owen, O. E., E. Kavle, R. S. Owen, M. Polansky, S. Caprio, M. A. Mozzoli, Z. V. Kendrick, M. C. Bushman, and G. Boden. 1986. A reappraisal of caloric requirements in healthy women. Am. J. Clin. Nutr. 44:1-19.

7. Ravussin, E., K. Acheson, O. Vernet, E. Danforth, and E. Jequier. 1985. Evidence that insulin resistance is responsible for the decreased thermic effect of glucose in human obesity. J. Clin. Invest. 76:1268-1273.

8. Segal, K. R., I. Lacayanga, A. Dunaif, B. Gutin, and F. X. Pi-Sunyer. 1989. Impact of body fat mass and percent fat on metabolic rate and thermogenesis in men. Am. J. Physiol. 256:E573-E579.

9. Shetty, P. S., R. T. Jung, W. P. T. James, M. A. Barrand, and B. A. Callingham. 1981. Postprandial thermogenesis in obesity. Clin. Sci. (Lond.). 60:519525.

10. Thorne, A., D. Hallberg, and J. Wahren. 1989. Meal-induced thermogenesis in obese patients before and after weight reduction. Clin. Physiol. 9:481-498.

11. Acheson, K. J., E. Ravussin, J. Wahren, and E. Jequier. 1984. Thermic effect of glucose in man: Obligatory and facultative thermogenesis. J. Clin. Invest. 74:1572-1580.

12. Newsolme, E. A. 1980. A possible metabolic basis for the control of body weight. N. Engl. J. Med. 302:400-405.

13. Golay, A., R. A. DeFronzo, E. Ferrannini, D. C. Simonson, D. Thorin, K. Acheson, D. Thiebaud, B. Curchod, E. Jequier, and J. P. Felber. 1988. Oxidative and non-oxidative glucose metabolism in non-obese Type 2 (non-insulin-dependent) diabetic patients. Diabetologia. 31:585-591.

14. Bonadonna, R. C., L. Groop, N. Kraemer, E. Ferranini, S. Del Prato, and R. A. DeFronzo. 1990. Obesity and insulin resistance: a dose-response study. Metab. Clin. Exp. 39:452-459.

15. Lillioja, S., and C. Bogardus. 1988. Obesity and insulin resistance: lessons learned from the Pima Indians. Diabetes Metab. Rev. 4:517-540.

16. Bogardus, C., S. Lillioja, D. M. Mott, C. Hollenbeck, and G. Reaven. 1985. Relationship between degree of obesity and in vivo insulin action in man. Am. J. Physiol. 248:E286-E291.

17. Segal, K. R., B. Gutin, A. M. Nyman, and F. X. Pi-Sunyer. 1985. Thermic effect of food at rest, during exercise, and after exercise in lean and obese men of similar body weight. J. Clin. Invest. 76:1107-1112.

18. Pedhazur, E. J. 1973. Multiple Regression in Behavioral Research. Holt, Rinehart, \& Winston, New York.

19. Segal, K. R., and F. X. Pi-Sunyer. 1989. Exercise and obesity. In Medical Clinics of North America. G. A. Bray, editor. W. B. Saunders Co., Philadelphia, 217-236.

20. Swindells, Y. E. 1972. The influence of activity and size of meals on caloric response in women. Br. J. Nutr. 27:65-73.

21. Young, J. C., J. L. Treadway, T. W. Balon, H. P. Gavras, and N. B. Ruderman. 1986. Prior exercise potentiates the thermic effect of a carbohydrate load. Metab. Clin. Exp. 35:1048-1053.

22. Maehlum, S., M. Grandmontagne, E. A. Newsholme, and O. M. Sejersted. 1986. Magnitude and duration of excess post-exercise oxygen consumption. Metab. Clin. Exp. 35:425-429.

23. Segal, K. R., B. Gutin, J. Albu, and F. X. Pi-Sunyer. 1987. Thermic effects of food and exercise in lean and obese men of similar lean body mass. Am. J. Physiol. 252:E110-E117.

24. National Diabetes Data Group. 1979. Classification and diagnosis of diabetes mellitus and other categories of glucose tolerance. Diabetes. 28:1039-1057.

25. Akers, R., and E. R. Buskirk. 1969. An underwater weighing system utilizing force cube transducers. J. Appl. Physiol. 26:649-652.

26. Wilmore, J. H. 1969. A simplified method for determination of residual lung volume. J. Appl. Physiol. 27:96-100.

27. Siri, W. E. 1961. Body composition from fluid spaces and density: analysis of methods. In Techniques for Measuring Body Composition. J. Brozek and A. Henschel, editors. National Academy of Sciences, Washington, DC. 223-244. 
28. Wasserman, K., and B. J. Whipp. 1975. Exercise physiology in health and disease. Am. Rev. Respir. Dis. 112:219-249.

29. DeFronzo, R. A., J. D. Tobin, and R. Andres. 1979. Glucose clamp technique: a method for quantifying insulin secretion and resistance. Am. $J$. Physiol. 237:E214-223.

30. Steele, R. 1959. Influence of glucose loading and of ingested insulin on hepatic glucose output. Proc. Natl. Acad. Sci. USA. 82:420-430.

31. Radziuk, J., K. H. Norwich, and M. Vranic. 1974. Measurements and validation of non-steady statte turnover rates with application to the insulin and glucose systems. Fed. Proc. 33:1855-1864.

32. Lusk, G. 1928. Elements of the Science of Nutrition. W. B. Saunders Co., New York. 65

33. Weir, J. B. 1949. New method for calculating metabolic rate with special reference to protein metabolism. J. Physiol. (Lond.). 109:1-9.

34. Segal, K. R., A. Edano, and M. Tomas. 1990 . Thermic effect of a meal over $3 \mathrm{~h}$ and $6 \mathrm{~h}$ in lean and obese men. Metab. Clin. Exp. 39:985-992.

35. Segal, K. R., A. Cruz-Noori, J. C. Santiago, and R. N. Santos. 1991 Reproducibility of the thermic effect of food in lean and obese men. FASEB (Fed. Am. Soc. Exp. Biol.) J. 5:A554.

36. Hugget, A. S., and D. A. Nixon. 1957. Use of glucose oxidase, peroxidase, and $O$-dianisidine in determination of blood and urinary glucose. Lancet. 2:368370 .

37. Herbert, V., K. S. Lau, C. W. Gottlieb, and S. J. Bleicher. 1965. Coated charcoal immunoassay of insulin. J. Clin. Endocrinol. Metab. 25:1375-1384.

38. Katz, J., and A. Dunn. 1967. Glucose-2-t as a tracer for glucose metabolism. Biochemistry. 6:1-5.

39. Hawk, P. B. 1978. Kjeldahl method. In Hawk's Physiological Chemistry. 14th edition. B. L. Oser, editor. McGraw-Hill, Inc., New York. 1214-1218.

40. Winer, B. J. 1971. Statistical Principles in Experimental Design. McGrawHill, Inc., New York.

41. Astrup, A., J. Bulow, N. J. Christensen, J. Madsen, and F. Quaade. 1986. Facultative thermogenesis induced by carbohydrate: a skeletal muscle component mediated by epinephrine. Am. J. Physiol. 250:E226-E229.

42. Reaven, G. M., J. Moore, and M. Greenfield. 1983. Quantification of insulin secretion and in vivo insulin action in nonobese and moderately obese individuals with normal glucose tolerance. Diabetes. 32:600-604.

43. Rizza, R. A., L. J. Mandarino, J. Genest, B. A. Baker, and J. E. Gerich. 1985. Production of insulin resistance by hyperinsulinemia in man. Diabetologia. 28:70-75.
44. Thiebaud, D., Y. Schutz, K. Acheson, E. Jacot, R. A. DeFronzo, J. P. Felber, and $\mathrm{E}$. Jequier. 1983. Energy cost of glucose storage in human subjects during glucose-insulin infusions. Am. J. Physiol. 244:E216-E221.

45. DeFronzo, R. A., R. Gunnarsson, O. Björkman, and J. Wahren. 1985. Effects of insulin on peripheral and splanchnic glucose metabolism in non-insulin dependent (Type II) diabetes mellitus. J. Clin. Invest. 76:149-155.

46. Radziuk, J. 1989. Hepatic glycogen in humans. II. Gluconeogenetic formation after oral and intravenous glucose. Am. J. Physiol. 257:E158-E169.

47. Flatt, J. P. 1978. The biochemistry of energy expenditure. In Recent Advances in Obesity Research II. G. A. Bray, editor. Newman Publishing, London. 211-228.

48. Katzeff, H. L., M. O'Connell, E. S. Horton, E. Danforth Jr., J. B. Young, and L. Landsberg. 1986. Metabolic studies in human obesity during overnutrition and undernutrition: thermogenic and hormonal responses to norepinephrine. Metab. Clin. Exp. 35:166-175.

49. Rowe, J. W. J. B. Young, K. L. Minaker, A. L. Stevens, J. Pallota, and L. Landsberg. 1981. Effect of insulin and glucose infusions on sympathetic nervous system activity in normal man. Diabetes. 30:219-225.

50. Bazelmans, J., P. J. Nestel, K. O'Dea, and M. D. Esler. 1985. Blunted norepinephrine responsiveness to changing energy states in obese subjects. Me tab. Clin. Exp. 34:154-160.

51. Devlin, J. T., and E. S. Horton. 1985. Effects of prior high-intensity exercise on glucose metabolism in normal and insulin-resistant men. Diabetes. 34:973-979.

52. Burstein, R., Y. Epstein, Y. Shapiro, I. Charuzi, and E. Karnieli. 1990. Effect of an acute bout of exercise on glucose disposal in human obesity. J. Appl. Physiol. 69:299-304.

53. Maehlum, S., P. Felig, and J. Wahren. 1978. Splanchnic glucose and muscle glycogen metabolism after glucose feeding during postexercise recovery. Am. J. Physiol. 235:E255-E260.

54. Swinburn, B. A., B. L. Nyomba, M. F. Saad, F. Zurlo, I. Raz, W. C. Knowler, S. Lillioja, C. Bogardus, and E. Ravussin. 1991. Insulin resistance associated with lower rates of weight gain in Pima Indians. J. Clin. Invest. 88:168173.

55. Arner, P. 1988. Control of lipolysis and its relevance to development of obesity in man. Diabetes Metab. Rev. 5:507-515.

56. Bessard, T., Y. Schutz, and E. Jequier. 1983. Energy expenditure and postprandial thermogenesis in obese women before and after weight loss. Am. J. Clin. Nutr. 38:680-693. 